\title{
Digital Storytelling as a Whole-Class Learning Activity: Lessons from a Three-Years Project
}

\author{
Nicoletta Di Blas ${ }^{1}$, Franca Garzotto ${ }^{1}$, Paolo Paolini ${ }^{1,2}$, and Amalia Sabiescu ${ }^{2}$ \\ ${ }^{1}$ HOC-LAB, Politecnico di Milano, Italy \\ \{nicoletta.diblas, franca.garzotto, paolo.paolini\}@polimi.it \\ ${ }^{2}$ TEC-LAB, Università della Svizzera Italiana, Lugano, Switzerland \\ \{paolinip, sabiesca\}@usi.ch
}

\begin{abstract}
This paper introduces PoliCultura, a project created by Politecnico di Milano for the Italian schools, which has just completed three years of deployment. Participating classes (with pupils aged between 4 and 18 years) are required to create their own multimedia story, using an authoring-delivery environment (1001stories) provided by Politecnico di Milano. PoliCultura has offered us the opportunity to investigate the prolonged use of digital storytelling authoring tools as a whole-class educational activity in a wide number of real educational settings: approximately 7,620 pupils from 381 classes have been involved in this project since its birth in 2006. From the overall PoliCultura experience and from the wide amount of qualitative and quantitative data collected from participants though online surveys, focus groups, interviews and contextual inquiry activities, we have learned a number of lessons that we discuss in the paper.
\end{abstract}

Keywords: Multimedia Storytelling, e-learning, education, adoption, educational benefits, case-study.

\section{Introduction}

From preschool to high school, storytelling is a very common educational experience that teachers propose to their students, in order to develop a variety of skills, e.g., communication capability, search, or (collaborative) tasks completion. Interactive multimedia technologies provide new means to support story authoring that in principle facilitate the work of teachers and pupils, limiting some drawbacks of working with physical tangible tools like pen and paper, and foster new forms of creativity, increasing engagement through interactivity. Still, the adoption of tools for digital storytelling in conventional educational settings is currently limited; most reported educational projects based on these systems are largely based on episodic, short-term experiences involving a limited number of teachers and students for a short period of time. In this respect, the PoliCultura project discussed in this paper represents an exception. Since the birth of PoliCultura in 2006, its storytelling tool has been used by over 7,620 students - from pre-schools to high schools - in our country, for whole class activities in the conventional school context spanning along several months and oftentimes repeated year after year by the same class. 
The paper presents PoliCultura and discusses the most relevant lessons learnt after the three years of life of this project. They pinpoint that that the conditions for adoption of a digital storytelling tool go beyond the design characteristics of technology per se, and highlight that even a relatively simple tool can promote students' creativity and achieve significant educational benefits.

\section{PoliCultura and the 1001stories Storytelling Tool}

PoliCultura is shaped as a competition for Italian schools requiring classes to complete a "multimedia narrative" on different subjects either proposed by organizers or freely selected by participants. The multimedia story has to be created using "1001stories" [1, 2], a streamlined authoring environment developed by HOC-LAB at Politecnico di Milano. The narrative format is based on a two levels structure: (1) a short story, consisting of a number of topics (from 4 to 7 are suggested); (2) a long story, consisting of the topics plus their sub-topics (from 3 to 5 suggested - Fig. 1). In the educational version of 1001 stories, each topic or subtopic is composed by an audio, its text transcript, and a slideshow of images with their captions which are displayed in sequence and synchronized (automatically) with the audio track. The professional version supports also other types of media such as Flash animations and videos. The user can explore topics and subtopics at her own pace; alternatively, she can enjoy the story passively, while the system automatically presents either the short or the long version of the narrative.

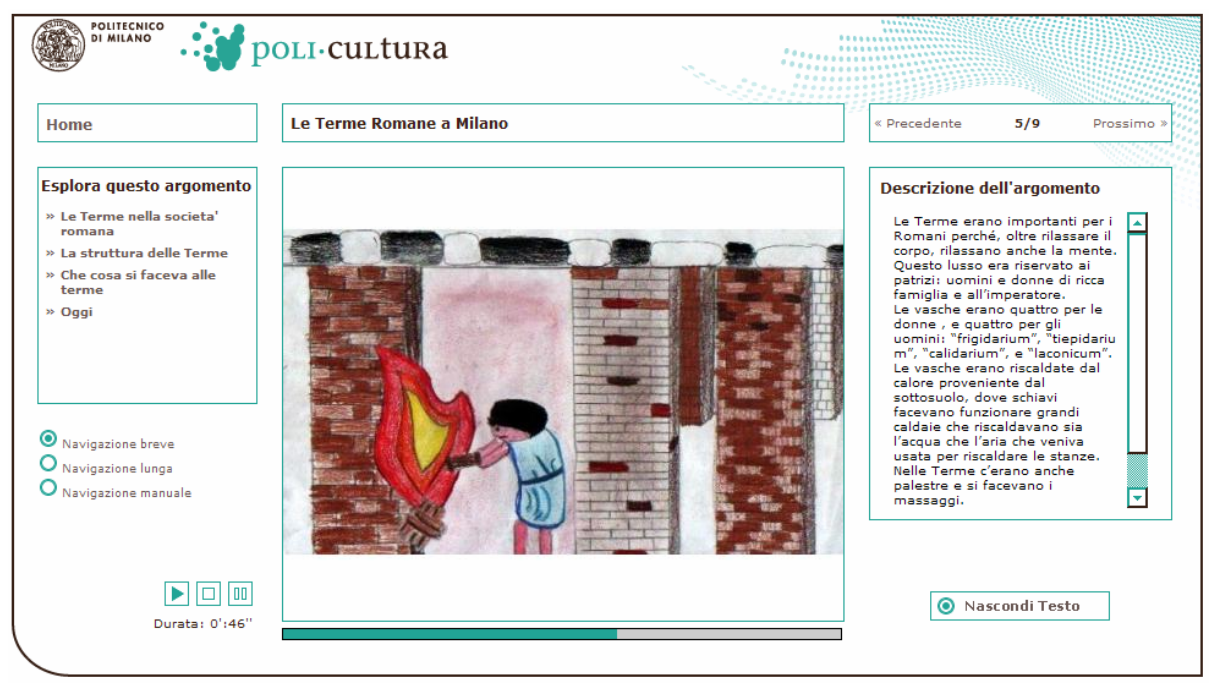

Fig. 1. "Milan during the Roman Empire Age" (primary school). The screenshot shows how the final story looks: on the left, there is the list of sub-topics of the topic on display (the "Roman Thermae of Milan" - as the title on top of the image reads). In the middle, a short slideshow of images runs (1 minute approximately) and eventually on the right there are the images' captions and the transcript of the audio comment. 
The main characteristics of the authoring environment which made it a success in wide-scale educational use are its accessibility, simplicity, and multichannel delivery. The tool is web-based. It supports a very natural way of defining and updating the narrative structure, allows very easy content upload of media units - mp3 files, jpeg images, and text, and is very intuitive to master: the average learning time is $20 \mathrm{~min}-$ utes, measured in primary schools. Once the narrative is completed a delivery engine (managed by Politecnico di Milano), generates at once several versions of the same narrative, for different delivery platforms: a web-site, a podcast version, an off-line version on CD-ROM (which can be distributed to students and families) and also a cellular phone version or a standard phone version (including interactive audio only). In the process of generation, the images are coupled together and synchronized with audio to generate video files. All the different interactive widgets are also generated, customized for each channel.

In the first year (2006/07) the competition targeted senior high schools only, since we deemed that the multimedia story task was too difficult for younger students; one primary school, however, made a "voluntary submission" that proved successful. In the year 2007/08 the competition was therefore opened to junior high schools and primary schools too. But again, one pre-school made a "voluntary submission". In the year 2008/09 all undergraduate school types were admitted. Table 1 shows the numbers of participating classes (corresponding to approximately 17,100 students). Of the participants initially registered, $75 \%$ completed the work and 50\% approximately submitted it to the competition (the evaluation process took almost 2 months).

Table 1. Participation to PoliCultura in 2006-2009 by school type. The columns on the right refer to the number of classes which accomplished and submitted the narrative, out of those initially registered.

\begin{tabular}{|c|c|c|c|c|c|c|c|c|c|c|}
\hline & \multicolumn{4}{|c|}{ Classes registered } & \multicolumn{3}{c|}{ Classes that submitted the narrative } \\
\hline Year & Total & $\begin{array}{c}\text { Pre- } \\
\text { school }\end{array}$ & $\begin{array}{c}\text { Primary } \\
\text { school }\end{array}$ & $\begin{array}{c}\text { Junior- } \\
\text { high } \\
\text { school }\end{array}$ & $\begin{array}{c}\text { High } \\
\text { school }\end{array}$ & Total & $\begin{array}{c}\text { Pre- } \\
\text { school }\end{array}$ & $\begin{array}{c}\text { Primary } \\
\text { school }\end{array}$ & $\begin{array}{c}\text { Junior- } \\
\text { high } \\
\text { school }\end{array}$ & $\begin{array}{c}\text { High } \\
\text { school }\end{array}$ \\
\hline $2008 / 09$ & $\mathbf{4 1 4}$ & 38 & 173 & 113 & 90 & $\mathbf{1 9 0}$ & 18 & 79 & 53 & 40 \\
\hline $2007 / 08$ & $\mathbf{3 3 8}$ & - & 149 & 98 & 91 & $\mathbf{1 3 5}$ & - & 57 & 38 & 40 \\
\hline $2006 / 07$ & $\mathbf{1 0 3}$ & - & - & - & 103 & $\mathbf{5 6}$ & - & - & - & 56 \\
\hline
\end{tabular}

The rest of this paper discusses some key lessons learnt after three years of deployment. Each lesson is first introduced by a general statement and then supported through data and examples from PoliCultura. Our discussion is based upon the wide amount of qualitative and quantitative data collected during the whole project using different protocols: our team's analysis of the multimedia stories, online surveys to teachers (approximately 60\% of teachers involved every year); focus groups and semi-structured interviews, involving respectively $10 \%$ and $5 \%$ of the set of participating teachers; contextual inquiry in a local primary school for over three months, with members of our team observing and working with 24 children aged 10-11 and their three teachers in the class or in the school computer laboratory. 


\section{Lessons Learnt}

\subsection{Conditions for Successful Adoption of Digital Storytelling in Schools}

In order to introduce an ICT-based activity such as digital storytelling in a class the basic ingredient is a committed teacher, open to innovation. The engagement of a teacher is in its turn facilitated by an effective tool, a good organization setting, and an adequate methodological support.

An excellent teacher can obtain great results even with a difficult class while excellent students cannot overcome the underperformance of a teacher. We ask each class to create one story, therefore the organization of the groups, the task assignment, and motivation, are crucial ingredients that the teacher only can obtain from a class. A teacher's effective participation is encouraged by some facilitating elements, some of which are related to the tool that has to be used. In our case, the use of 1001stories has proved an easy job (see previous section). At the same time, the result is a kind of "magical" for teachers, pupils, and families [3]: with a single effort, a website, a CD-ROM, a podcast, and a version for cellular phone are produced. This makes the experience highly rewarding and builds confidence with the use of technology.

When facing a complex activity like creating a digital story, a good organization setting is crucial: in our experience with PoliCultura, the main reason (detected via online surveys) for dropping out is underestimation of the work needed. The other motivation is conflict of schedule with curricular activities. Both these reasons do not concern the storytelling activity per se but rather the organizational context in which it should take place. Another critical organizational factor is the principal's approval, for permission to take time from other curricular activities, or for using the computer laboratories, etc.

Eventually, though PoliCultura participants have shown a high degree of autonomy over the years, a good support both in terms of precise guidelines and examples to look at is important. We have collected and made available online a sizable library of the works done by the classes [4]: this provides a strong drive for imitation. In some cases works done by a class had been used in another to introduce a curricular topic, e.g., "Milan during the Roman Empire Age" - see Fig. 1, was adopted to discuss Roman civilization in the classroom.

The overall lesson is: innovative activities in schools should give a pivotal role to teachers. They are the ones that can transform any idea in a real teaching and learning project.

\subsection{Anchoring Stories to a Shared, Real-Life Context}

Collective storytelling activities can be more motivating and engaging for students if their subject is anchored to a whole class, shared, real-life experience. This choice does not affect creativity (most stories, especially for younger pupils, go far beyond the mere realistic description of the experience) nor does it prevent the introduction of fictional elements in the narrative.

Most of the stories generated by schools (at all levels) in PoliCultura are rooted in a real-life experience undertaken by the entire class, e.g., a trip, a visit to a museum, a research, or a science experiment. As an example, one of the PoliCultura finalist stories (primary school) in the year 2008/09 was based upon a class trip in a forest region. Around this real-life experience students built a fictional tale of magic 
encounters with mysterious creatures. In this case, the real-life experience created a strong context for the whole narrative. Additional examples are discussed below. In our opinion, there are two possible reasons that motivate participants to choose a reallife context for building a narrative: (1) PoliCultura competition asks for a collective narrative (rather than a collection of individual pupil's stories) and this strongly calls for reference to a shared common ground [5]; (2) as situated learning theory explains [6], a learning process is a function of the activity, context and culture in which it occurs: selecting a real life experience, teachers obtain two advantages: (a) more interest for the activity itself (e.g., a visit to a museum); (b) a long lasting effect of the experience being reinterpreted by the storytelling activity.

Example 1. Anchor: Visiting Cultural Heritage Settings (Primary School). For creating "Milan during the Roman Empire Age" (Fig. 1), a class of 10-11 years old pupils visited the local Archaeological Museum and some relevant spots in the city of Milan, took pictures, made drawings and gave their own interpretation of the city's Roman historical past [7]. Motivated by the storytelling activity, children involved families to visit the museum again. Among other educational benefits [7], this storytelling experience had a long lasting effect: interviews with parents, pupils and teachers two years later highlighted that they remember almost everything about it!

Example 2. Anchor: A Research on Local History (Junior High School). A class of junior high school children from a small town in Sicily, in the mafia's territory, anchored their narrative to a socially difficult context. They told us about those who fought against mafia, provocatively calling them "men of honour" (the way mafia people call themselves) and built a powerful, brave story based on a wide class research activity (Fig. 2, left). The storytelling activity generated motivation for the research and, at the same time, it helped students to "interiorize" the main themes of it, and fostered in youngsters a deep reflections on their feelings about mafia.

Example 3. Anchor: A School Lab Activity (Pre-school). The story of an elf teaching kids how to transform stones into beautiful artefacts frames the application

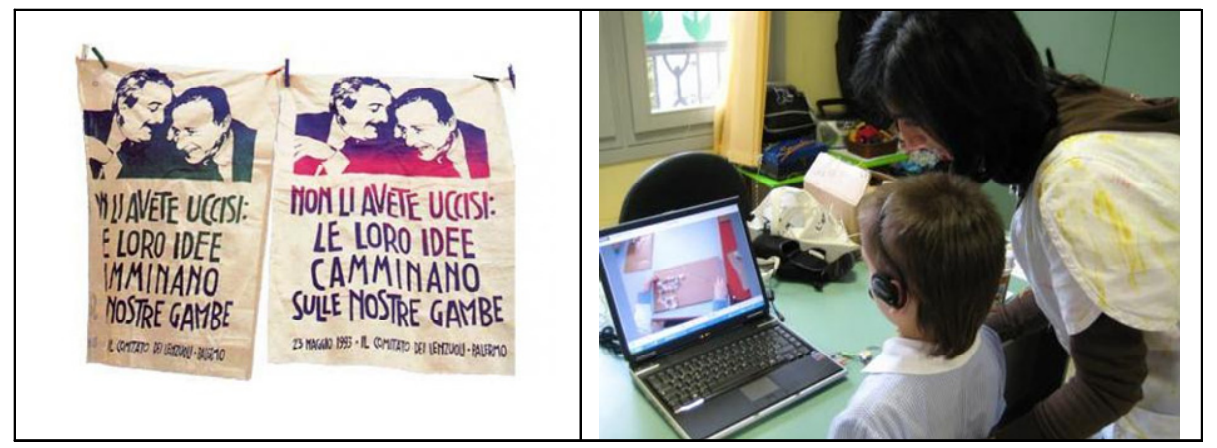

Fig. 2. On the left, one of the images of the application "Men of honour" about those people who bravely fought Italian mafia (junior high-school). The line reads: “... their ideas walk on our legs". On the right, recording audio for "Stones, pebbles and rocks" (pre-school). 
"Stones, pebbles and rocks" that reports on an art-lab done in class (Fig. 2, right). The results of this project show that even very young children (aged 5) can be involved in a digital storytelling activity [3], in relationship with a meaningful and shared class activity. Interviews with teachers detected that one of the pupils, with minor personality problems and often not involved in class activities, specifically asked for a role in the storytelling and made some of the most touching recordings.

\subsection{Narrative Paradigms are Multiple}

An "effective" story-telling tool must strike a balance between being easy to use (lesson 1) and not hindering the users' creativity. Student can bend to their communication needs even a tool with a limited set of functionalities and narrative formats, and make it support a number of different and unexpected storytelling paradigms.

We have seen in Sect. 2 that 1001stories is apparently quite "rigid": the information architecture is fixed (a set of topics and sub-topics) and the kind of content that users can insert is limited (text, images, and audio). In addition, all users are provided with the same set of guidelines that distil our own experience in using the tool. Still, the submissions we receive display a surprising array of different "interpretations" of the format that show how "even with just a black and white pencil you can create a masterpiece" (quote from European architect Mario Botta).

Example 1. "Rules Breaking": The Circus (Primary School). "The Circus", based on a one-year school activity, "breaks" our guidelines in a number of ways: (a) audios are extremely short - they all last less than 10 seconds, while the recommended length is one minute or more; (b) in the audio, students do not read a narrative but play the characters" parts like "experienced actors"; (c) for each topic of the narrative there is only one image, instead of the 4-6 images recommended by our guidelines. Therefore the rhythm of the narrative is really fast-paced. The result, however, is an engaging set of lively stories in comic-style, animated by characters invented by the children.

Example 2. "Rules Bending": Montevecchio (Primary School). The application "Montevecchio and its surroundings" skilfully blends two literary genres: the "short story" (the set of main topics) is a fiction about two kids learning from talking animals how to care about the environment. The "details" (i.e., the sub-topics) illustrate various natural-science issues from a more objective perspective.

Example 3. "Unexpected Content": Together with You, Grandpa (Junior High School). The narrative "Together with you, Grandpa" is grounded on a school project for helping elderly people who are left alone in specialized communities. If most of the narrative is quite traditional, the end of the narrative introduces some "audio letters" from the elderly to the children who paid them a visit. The result of this unexpected content is engaging and touching (Fig. 3). 


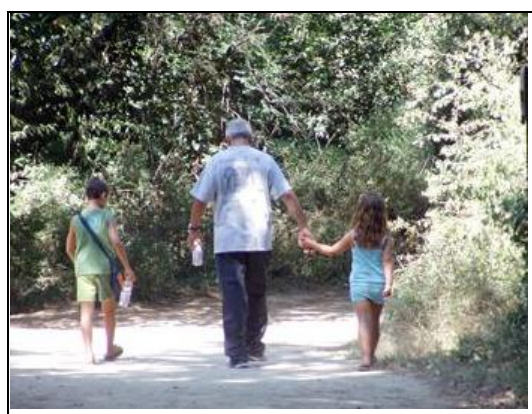

Dear children,

I am Armando and I was very happy to meet you. That morning I felt really good. I wanted to tell you that I worked hard in my life for my 6 sons and 5 grandchildren, whom I love very much. When you told me I am the most beautiful grandpa in the world - it made me smile. But I'm so proud of it. I eagerly wait for you. Thank you for keeping me company and for your letters.

Armando, the most beautiful grandpa in the world

Fig. 3. Two pieces of content from the narrative "Together with you, Grandpa" (Junior High School): A picture (left) and the transcript of an audio-letter to the kids, recorded by "grandpa" Armando

\subsection{Learning Benefits}

The introduction of well supported digital storytelling in schools can be an extraordinary facilitator for a wide range of substantial educational benefits, e.g., acquisition and consolidation of knowledge and skills, heightened engagement, motivation towards learning activities, and also acquisition of digital literacy skills.

The learning experience provided by PoliCultura is multifaceted: building a narrative implies a number of activities ranging from focusing the idea, organizing group work, designing the plot, writing the texts, recording the audios, selecting/adjusting the images. From our experience, pupils approach the subject matter of the narrative in a way that enables a structured view of the theme and its components, and fosters interest, higher retention rate, and deep understanding of the story subject. At the same time, students improve their teamwork capabilities: the thick social interaction engages students, including those with special needs, more than normal school activities do.

In PoliCultura, we performed a specific research on educational benefits every year, in the context of the wider study discussed in Sect. 2. The learning impact was measured on two macro-dimensions: the cognitive level (which involves knowledge and intellectual skills) and the affective level (referring to the way learners relate to things and activities emotionally - feelings, values, motivation, and attitude) [8].

Along the three years of PoliCultura, 318 adult educators overall participated in this study: 55 educators in the first year, 110 in the second and 153 in the third year, from pre-school, primary, junior high school and high school. Since lack of space prevents us from providing a detailed analysis of the whole study, we discuss here the results from the online questionnaire on learning outcomes submitted to teachers at the end of the storytelling experience in the $3^{\text {rd }}$ project year.

We identified a list of educational benefits and asked respondents to i) assess the achievement of each benefit in the PoliCultura project against the achievement of the same benefit as it results in "normal" school activities, at a comparable effort on a comparable matter, and ii) compare the overall educational impact. Items were scored on a 5-point Likert scale (1: much lower; 5: much higher). The same questionnaire 
also collected free comments that were then classified according to their pertinence to the different benefits and coded for analytical purposes.

The overall learning impact was evaluated optimal (with respect to comparable traditional activities) by $76.5 \%$ of the teachers and good by $22.2 \%$. As Table 2 shows, $77.6 \%$ of the teachers think that PoliCultura engages children significantly more than normal school activities. A teacher said: "I believe the educational benefits are obtained much more effectively than with usual frontal lessons. Students are well engaged because they get to use computers, which they are very fond of." $67.3 \%$ of the teachers think that the storytelling activity generates higher interest in the subject matter. $62.1 \%$ underline that pupils develop a better understanding of the logical connections and relations among various themes addressed by their stories.

Table 2. Excerpt of learning benefits evaluation of the PoliCultura experience as compared to regular didactic activities (from questionnaires administered in 2008/09 to 153 educators)

\begin{tabular}{|l|c|r|r|r|c|}
\hline \multirow{2}{*}{ Educational benefit } & \multicolumn{5}{|c|}{ Achievement with respect to regular teaching activities } \\
\cline { 2 - 6 } & I[much lower] & 2 [lower] & 3 [equal] & 4 [better] & 5 [much better] \\
\hline Deep understanding & $0.00 \%$ & $0.70 \%$ & $4.60 \%$ & $\mathbf{5 4 . 6 0 \%}$ & $40.50 \%$ \\
\hline Content organization skills & $0.00 \%$ & $0.70 \%$ & $9.20 \%$ & $\mathbf{6 2 . 1 0 \%}$ & $28.10 \%$ \\
\hline Retention & $0.00 \%$ & $0.70 \%$ & $5.90 \%$ & $39.50 \%$ & $\mathbf{5 4 . 2 0 \%}$ \\
\hline Interest in a subject matter & $0.00 \%$ & $0.70 \%$ & $3.30 \%$ & $28.90 \%$ & $\mathbf{6 7 . 3 0 \%}$ \\
\hline Engagement & $0.00 \%$ & $0.00 \%$ & $2.60 \%$ & $20.30 \%$ & $\mathbf{7 7 . 6 0 \%}$ \\
\hline Technical abilities & $0.00 \%$ & $1.30 \%$ & $8.50 \%$ & $35.90 \%$ & $\mathbf{5 4 . 6 0 \%}$ \\
\hline Communication abilities & $0.00 \%$ & $0.00 \%$ & $7.90 \%$ & $\mathbf{5 1 . 0 0 \%}$ & $41.40 \%$ \\
\hline Teamwork capacities & $0.00 \%$ & $0.00 \%$ & $6.60 \%$ & $38.20 \%$ & $\mathbf{5 4 . 9 0 \%}$ \\
\hline
\end{tabular}

In addition, all the teachers (67\% rating 5, and 33\% rating 4) found that using 1001 stories had been a powerful tool for achieving "media literacy", i.e. the ability "to effectively create, use and communicate information" using new technologies [9]. A teacher said: "The children had the chance to use the computer skills they were already in command of to communicate their experience". Some teachers underlined the effectiveness of storytelling for involving children with mental or physical difficulties, or children isolated from the group. A teacher mentioned: "In my class there is a dyslexic kid. He tried to record his part some 15, even 20 times and he did not want to give up. The whole class stood around him cheering and in the end he made it". A teacher reported that their project was also an occasion to know her students better, "especially some kids who proved invaluable in this work, whereas in regular school activity they do not usually stand out". One teacher even declared his intention to use the Policultura experience "to make other teachers understand that using multimedia can make interesting those topics which are usually found boring". 


\section{Related Work}

Equipping children with storytelling skills starting from early childhood is proven to support their development, by helping them express and assign meaning to the world [10], [11], or for developing specific abilities such as tasks-completion and problemsolving [12-13]. The value brought by technology in supporting children storytelling and story authoring has been demonstrated by a series of studies [10], [14] and applied in the development of a very rich array of authoring tools, both commercial and resulting from academic research. When it comes to actual usage, however, the application area of digital story authoring tools remains in most cases small-scale.

In the following, we look at a series of projects involving the use of story authoring tools with a potential - not yet exploited - for wide integration in pre-school or school curricula, focusing on aspects of collaboration in the authoring experience. For a comparative look, we will also present one example of large adoption of an online digital story authoring environment supported by a broadcasting corporation. Finally, we will refer to widely employed solutions for implementing digital storytelling in the classroom, by using off-the-shelf technology and software.

The authoring process can be integrated in the scholarly activities on-site, or can involve collaboration of children at a distance. KidPad [15-16] is a tool involving children in synchronous co-presence collaborative story authoring, by using drawing, typing and hyperlinking functionalities optimized for synchronous collaborative input (e.g., multiple mice) on a 2-dimensional zoomable space. Further research has added tangible interface and gesture recognition technology to KidPad [17], resulting in a "magic carpet" which can support collaboration in larger groups, story retelling and reenactment as complementary to story creation. Playful collaboration in the creation of stories using the playground metaphor is also explored in the projects StoryMat [14], [18] and POGO [10]. Synchronous distance-based collaboration for authoring stories in 2D and 3D virtual environments has been exploited in projects such as FaTe2 [19], MOOSE crossing [20] or MyStoryMaker (work in progress) [21]. PUPPET [22] is an example of a virtual environment used for teaching basics of drama production and enactment to children. An approach to narrative development which shifts the boundaries between author and user is Emergent Narrative (EN) [23], referring to stories in which the advancement of the narrative is determined by the interaction between characters, controlled by the user's choices. The active role taken by users in EN has been exploited for educational purposes through the introduction of role-play elements, allowing children to become aware of the consequences of their actions by acknowledging the response triggered in the virtual characters with which they interact. [24].

Most of the projects listed above and many similar others with potential of enriching educational experiences have a limited adoption rate. In trying to tap the possibilities as well as obstacles of extending the range of coverage of such projects, let us look, apart from our experience, at the successful implementation of one project in which a story authoring tool has been used by tens of thousands of children.

StoryBuilder [25], produced by CBC4Kids (Canadian Broadcasting Corporation) is a web-based tool which enables children to create multimedia commix-style stories in three modalities: contribute to an on-going story by adding the next page; use preexisting elements to create a story from scratch; collaborative page-by-page creation 
of a story among friends by editing and sending it by email. The project encountered wide success, with over 150,000 visits to the site and 2,200 submissions during the four months pilot phase. In this project, wide adoption was facilitated by a series of factors ranging from the simplicity of the tool (balancing the aim to leave space for creativity and the constraints of using ready-made story elements), easy access (log-in was required only after a submission was created), an easy-to-appropriate storytelling style based on comic-books conventions, flexibility, as well as the existence of various modes of contribution and various types of collaboration.

While success projects of wide adoption of authoring tools such as StoryBuilder are still few, digital storytelling found its way in the curriculum of many schools without making use of custom-made story authoring tools. By using regular videoediting software (from Windows MovieMaker to Apple Final Cut Pro) and sets of guidelines for creating compelling stories, teachers have engaged students in telling digital stories across a wide range of disciplines. These initiatives (e.g. [26-29]) prove that the motivation and the interest to integrate digital storytelling in the curriculum exist, and also pinpoint that low costs, simplicity and wide availability of authoring tools are essential aspects for its integration.

\section{Conclusions}

Few existing research investigate a massive, long term use of digital storytelling tools for educational purposes in real scholarly contexts. This paper has discussed the lessons learnt from a wide study carried on in the context of a three-years project PoliCultura - during which we could explore how a multimedia storytelling tool has been used by around 7,620 students - in a wide number of Italian educational institutions of all grades - from pre-schools to high schools, from 2006 to 2009.

Current research on digital storytelling has been largely focused on developing and evaluating new systems and new forms of user experiences [10], [14-16], [18-19]. They oftentimes involve a sophisticated integration of different technologies and ad hoc devices, and are typically adopted for a relatively short time in real school contexts before being definitively abandoned. Indeed, such "high-tech" solutions require the availability of high budget and ICT specialists, and are seldom affordable by a typical educational context and sustainable in the medium-long term.

Our study has pinpointed some fundamental factors for large-scale, prolonged, and repeated use of storytelling authoring systems in schools: the pivotal role of teachers as drivers for adoption, low-cost, low-tech, simplicity of the tools, and availability of methodological support to the development process.

Our study has also highlighted that easy-to-understand, built-in narrative formats constrain some design aspects of a digital story but indeed simplify the use of an authoring tool, and foster its adoption without preventing students to express their creativity and to invent original narrative forms. A simple (albeit powerful) system as "1001stories" has an apparent rigidity (the predefined two-level structure of the story), but our studies have shown that creative teachers and pupils can circumvent such constraints and use the tool in original and effective ways: The variety of solutions developed by PoliCultura participants (in terms of rhetoric arrangement and 
styles) is amazing and very interesting, and we have started a research project to systematically analyze them.

Finally, we have pinpointed various types of measurable benefits derived from a non episodic engagement of learners with digital storytelling activities at collective level, i.e., when the full class is involved as a whole. Collective storytelling is quite different from individual story-telling, where an individual (even if part of a community) is called to express his/her own narrative. In a collective storytelling activity, educational benefits are global for the participants, measurable at the levels of acquisition of knowledge and skills, but also at the level of shared expression forms and facilitated social interaction.

\section{References}

1. Di Blas, N., Bolchini, D., Paolini, P.: Instant Multimedia: A New Challenge for Cultural Heritage. In: Bearman, D., Trant, J. (eds.) Museums and the Web (2007),

http://www. archimuse.com/mw2007/papers/diBlas/diBlas.html (accessed July 7, 2009)

2. Di Blas, N., Garzotto, F., Poggi, C., Torrebruno, A.: Instant Multimedia for Educational Setting: A Success Story. In: ED-MEDIA 2008, pp. 538-544. AACE, Chesapeake (2008)

3. Di Blas, N., Boretti, B.: Interactive storytelling in pre-school: a case-study. In: 8th International Conference on Interaction Design and Children, pp. 44-51. ACM, New York (2009)

4. Library of storytelling examples produced by schools as part of the PoliCultura Project, http: / /www. policultura. it/background (accessed September 16, 2009)

5. Clark, H.H.: Using Language. Cambridge University Press, Cambridge (1996)

6. Brown, J.S., Collins, A., Duguid, P.: Situated cognition and the culture of learning. Educational Researcher 18(1), 32-42 (1989)

7. Garzotto, F., Paolini, P.: Bringing Cultural Heritage into Primary School Classrooms through Web technology: The "Milano Romana Tecnologica" Case-Study. In: Bearman, D., Trant, J. (eds.) Museums and the Web 2008, pp. 103-115. Archives \& Museum Informatics, Montreal (2008)

8. Krathwohl, D.R., Bloom, B.S., Masia, B.B.: Taxonomy of Educational Objectives: The Classification of Educational Goals. In: Handbook II: Affective Domain. David McKay Co., Inc., New York (1964)

9. US National Commission on Library and Information Science: The Prague Declaration: Towards an Information Literate Society (2003),

http://www.infolit.org/international_conference_2003/

PragueDeclaration.pdf (accessed July 7, 2009)

10. Decortis, F., Rizzo, A.: New active tools for supporting narrative structures. Personal and Ubiquitous Computing 6(5-6), 416-429 (2002)

11. Madej, K.: Towards digital narrative for children: from education to entertainment, a historical perspective. Computers in Entertainment 1(1), 1-17 (2003)

12. Kritzenberger, H.: Architectures for constructive multimedia learning environments: challenges for narrative teaching models. In: ED-MEDIA 2004, pp. 88-95. AACE, Chesapeake (2004)

13. Richard, C., Williams, D., Ma, Y.: Implications of Narrative and Interactive Narrative for the Design of Problem-based Learning Environments. In: ED-MEDIA 2006, pp. 24102414. AACE, Chesapeake (2006) 
14. Cassell, J., Ryokai, K.: Making Space for Voice: Technologies to Support Children's Fantasy and Storytelling. Personal Ubiquitous Computing 5(3), 169-190 (2001)

15. Druin, A., Stewart, J., Proft, D., Bederson, B., Hollan, J.: KidPad: a design collaboration between children, technologists, and educators. In: CHI 1997, pp. 463-470. ACM, New York (1997)

16. Hourcade, J.P., Bederson, B.B., Druin, A., Taxén, G.: KidPad: collaborative storytelling for children. In: CHI 2002 Extended Abstracts, pp. 500-501. ACM, New York (2002)

17. Stanton, D., Bayon, V., Neale, H., Ghali, A., Benford, S., Cobb, S., Ingram, R., O'Malley, C., Wilson, J., Pridmore, T.: Classroom collaboration in the design of tangible interfaces for storytelling. In: CHI 2001, pp. 482-489. ACM, New York (2001)

18. Ryokai, K., Cassell, J.: StoryMat: a play space for collaborative storytelling. In: CHI 1999 Extended Abstracts, pp. 272-273. ACM, New York (1999)

19. Garzotto, F., Forfori, M.: FaTe2: storytelling edutainment experiences in 2D and 3D collaborative spaces. In: 5th International Conference on Interaction Design and Children, pp. 113-116. ACM, New York (2006)

20. Bruckman, A.: MOOSE Crossing: Construction, Community and Learning in a Networked Virtual World for Kids. Ph.D. thesis. MIT, Cambridge (1997)

21. McKinley, B., Lee, Y.: Mystorymaker. In: CHI 2008 Extended Abstracts, pp. 3219-3224. ACM, New York (2008)

22. Marshall, P., Rogers, Y., Scaife, M.: PUPPET: a Virtual Environment for Children to Act and Direct Interactive narratives. In: 2nd Workshop on Narrative and Interactive Learning Environments, Edinburgh, UK (2002)

23. Aylett, R.: Narrative in Virtual Environments - Towards Emergent Narrative. In: Mateas, M., Sengers, P. (eds.) Narrative Intelligence. Papers from the 1999 Fall Symposium. Technical Report FS-99-01, pp. 83-86. AAAI Press, Menlo Park (1999)

24. Figueiredo, R., Brisson, A., Aylett, R., Paiva, A.: Emergent stories facilitated. In: Spierling, U., Szilas, N. (eds.) ICIDS 2008. LNCS, vol. 5334, pp. 218-229. Springer, Heidelberg (2008)

25. Antle, A.: Case study: the design of CBC4Kids' StoryBuilder. In: 2nd Int. Conf. on Interaction Design and Children, pp. 59-68. ACM, New York (2003)

26. Feher, P.: Towards effective student-centered, constructivist learning: Build Your Own Digital Story! In: ED-MEDIA 2008, pp. 2364-2367. AACE, Chesapeake (2008)

27. Oliveira, A., Roso, M., Miranda, R.: Construction of Collective Imagetic Narratives: Challenges in Teaching and Learning Processes within the Digital Culture. In: ED-MEDIA 2008, pp. 2998-3006. AACE, Chesapeake (2008)

28. Susono, H., Shimomura, T., Kagami, A., Ono, E.: Creating Digital Stories by College Students in Project Based Learning. In: ED-MEDIA 2008, pp. 2730-2734. AACE, Chesapeake (2008)

29. Pierre, F.: Krik Krak: Eyewitness to My Heritage, a Digital Storytelling Tale. In: Proc. ED-MEDIA 2006, p. 2602. AACE, Chesapeake (2006) 